\title{
Modified Suspender Force Calculation Method of Suspension Bridge
}

\author{
Li Dongdong $^{1} \&$ Liao Xiaofang ${ }^{1}$ \\ ${ }^{1}$ Department of Civil engineering, Chongqing Jiaotong University, Chongqing, China \\ Correspondence: Li Dongdong, Department of Civil Engineering, Chongqing Jiaotong University, Chongqing \\ 400074, China. Tel: 86-150-8673-9828. E-mail: 616234757@qq.com
}

Received: February 13, 2014

doi:10.5539/mas.v8n3p37

\author{
Accepted: March 10, $2014 \quad$ Online Published: April 8, 2014 \\ URL: http://dx.doi.org/10.5539/mas.v8n3p37
}

\begin{abstract}
Through the mechanical analysis of the suspenders of suspension bridge, the suspender is assumed to be a tensional beam pined at one end and elastically supported at the other end, basing on which the vibration shape function for axial tension beam is established and corresponding formulas to calculate the cable force are obtained. The relationship between the elastic support stiffness and the transverse difference between two ends is obtained according to numerous analyses on a suspension bridge. The suspender forces of Qingcaobei Yangtze River Bridge are respectively calculated using traditional method and the method in this paper. Comparisons between two calculation results are then conducted which proves that the method in this paper can meet the precision of suspenders with different lengths, especially to the short suspenders, whose calculation deviation can be controlled in the engineering allowance.
\end{abstract}

Keywords: suspension bridge, suspender force, calculation method

\section{Introduction}

The cable force tester is usually used for measuring the suspension bridge cable force in engineering. In the testing theory, the suspender is assumed to be a chord whose transverse stiffness can be neglected and then the cable force can be calculated according to the conversion relation between the frequency and the chord tension. Above calculation method is relative accurate for long suspender but it can't serve for short suspender whose transverse stiffness can't be neglected. Much work has been done to solve this problem, such as simplifying the short suspender to be a beam consolidated in both ends, which can be used for the cable force calculation of the cable stayed bridge with the cable consolidated in the intersection between the main beam and cable tower. However, when it comes to the suspension bridge, this simplification can't meet the factual suspender boundary condition any more. Hence, a modified simplification is correspondingly made to specially calculate the tension force of the suspension bridge's short suspender shown in Figure 1 where $\Delta$ stands for the displacement difference between each ends of the suspender (Figure 1(b)), $\mathrm{k}$ stands for the elastic supported stiffness of the suspender (Figure 1(c)).

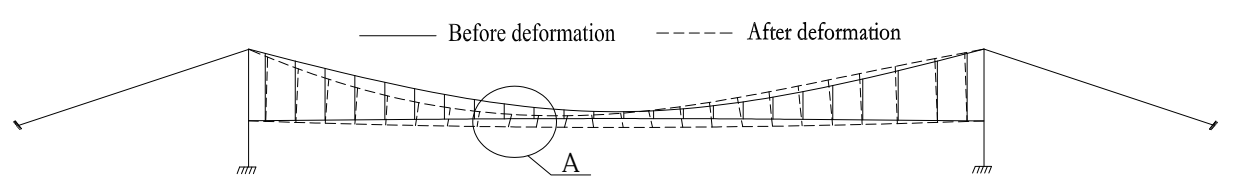

(a)

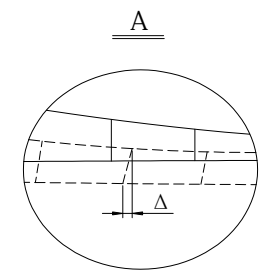

(b)

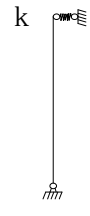

(c)

Figure 1. Simplification of suspension bridge suspender 


\section{The Calculation Principle}

Three assumptions are made to the calculating model as follows:

a) The elastically supported beam always works in elastic stage.

b) The section is constant along beam length and the material is homogeneous, isotropic.

c) The vibration of the beam is tiny.

\subsection{Establishment of the Shape Function}

Research have proved that the shape function of the uniform simply supported beam can be expressed through the sine function

$$
\psi_{0}(x)=\sin \left(\frac{\pi x}{l}\right)
$$

In this equation, $l$ stands for the calculating length of the simply supported beam. Define the point at the left end as the original point and the beam axis direction as $\mathrm{X}$-axis of the coordinate system (Figure 2).

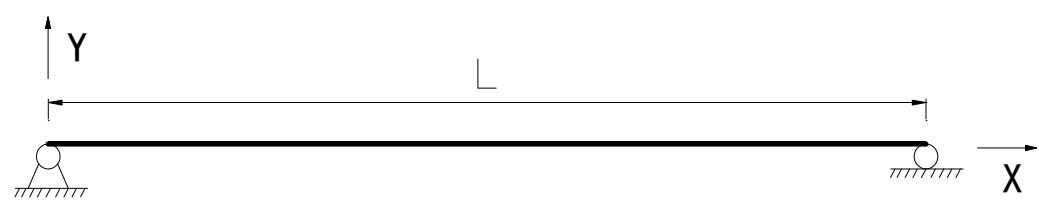

Figure 2. Simply supported beam

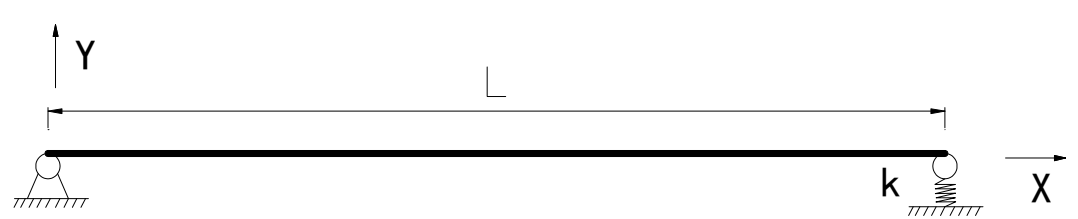

(a)

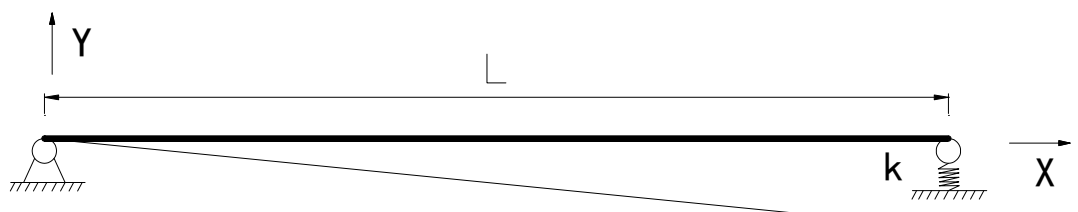

(b)

Figure 3. Elastically supported beam

As to the elastically supported beam (Figure 3(a)), its shape function must be firstly determined before calculating the natural frequency when using Rayleigh method. Principally, the beam shape function can be arbitrarily selected once the geometrical boundary conditions can be satisfied. It has been proved that the engineering accuracy can be basically approved taking the deformed shape under self-weight as the shape function to calculate the natural frequency. And when the beam is rigid, the vertical displacement of the elastically supported beam is

$$
\psi_{1}(x)=\frac{m g}{2 k l} x
$$

Where $l$ stands for the length of the calculating length of the simply supported beam; $m$ is the beam mass; $g$ is gravity acceleration; $k$ is the stiffness of the elastic support.

According to the superposition principle of linear elastic body, the shape function of the elastically supported beam can be assumed as follows

$$
\psi(x)=\psi_{0}(x)+\psi_{1}(x)=\sin \left(\frac{n \pi x}{l}\right)+\frac{m g}{2 k l} x
$$


In which $\mathrm{n}$ stands for the order of the shape function and the other symbols represent the same meanings as mentioned above.

It can be derived that when $x=0, \psi(0)=0$ and when $x=l, \psi(l)=\frac{m g}{2 k}$ which satisfy the geometrical boundary condition of the beam. Therefore, Equation (1) can be taken as the shape function of the elastically supported beam.

\subsection{Deduction of Relationship between Frequency and Axial Force}

The location of elastically supported beam in global coordinate system at any time can be determined as

$$
v(x, t)=\psi(x) \cdot Z(t)=\psi(x) \cdot Z_{0} \sin (\omega t), x \in[0, l]
$$

Here $t$ and $w$ respectively mean the time and circular frequency, and basing on which the bending strain energy can be obtained:

$$
V_{B}=\frac{1}{2} \int_{0}^{l} E I \cdot\left(\frac{\partial^{2} v}{\partial x^{2}}\right)^{2} \cdot d x=\frac{1}{2} Z_{0}^{2} \sin ^{2}(\omega t) \cdot \int_{0}^{l} E I \cdot\left[\psi^{\prime \prime}(x)\right]^{2} \cdot d x
$$

Where $E I$ stands for the transverse bending stiffness.

And the maximum bending strain energy

$$
V_{B \max }=\frac{1}{2} Z_{0}^{2} \cdot \int_{0}^{l} E I \cdot\left[\psi^{\prime \prime}(x)\right]^{2} \cdot d x
$$

The axial tensile strain energy

$$
V_{t}=\frac{1}{2} \int_{0}^{l} T \cdot\left(\frac{\partial v}{\partial x}\right)^{2} \cdot d x=\frac{1}{2} Z_{0}^{2} \sin ^{2}(\omega t) \cdot \int_{0}^{l} T \cdot\left[\psi^{\prime}(x)\right]^{2} \cdot d x
$$

The maximum axial tensile strain energy

$$
V_{t \max }=\frac{1}{2} Z_{0}^{2} \cdot \int_{0}^{l} T \cdot\left[\psi^{\prime}(x)\right]^{2} \cdot d x
$$

Kinetic energy of the elastically supported beam

$$
W=\frac{1}{2} \int_{0}^{l} m \cdot\left(\frac{\partial v}{\partial t}\right)^{2} d x=\frac{1}{2} Z_{0} \omega^{2} \sin ^{2}(\omega t) \cdot \int_{0}^{l} m \cdot\left[(\psi(x)]^{2} d x\right.
$$

The maximum kinetic energy of the elastically supported beam

$$
W=\frac{1}{2} Z_{0} \omega^{2} \cdot \int_{0}^{l} m \cdot\left[(\psi(x)]^{2} d x\right.
$$

The maximum kinetic energy is equal to the maximum strain energy

$$
W=V_{B \max }+V_{t \max }
$$

Then, the relationship between the frequency and axial force can be expressed as follows

$$
\begin{gathered}
\omega^{2}=\frac{\int_{0}^{l} E I \cdot\left[\psi^{\prime \prime}(x)\right]^{2} d x+\int_{0}^{l} T \cdot\left[\psi^{\prime}(x)\right]^{2} d x}{\int_{0}^{l} m \cdot[\psi(x)]^{2} d x} \\
\omega=2 \pi f
\end{gathered}
$$

Or

$$
T=\frac{4 \alpha \pi^{2} f^{2} \int_{0}^{l} m \cdot[\psi(x)]^{2} d x-\int_{0}^{l} E I \cdot\left[\psi^{\prime \prime}(x)\right]^{2} d x}{\int_{0}^{l}\left[\psi^{\prime}(x)\right]^{2} d x}
$$

Where $f$ stand for engineering frequency, $\alpha$ stands for the correction coefficient of suspender force and can be obtained from the following equation 


$$
\alpha=\left\{\begin{array}{lc}
0.75 & 0 m \leq l \leq 20 m \\
0.90 & 0 m \leq l \leq 20 m \\
1.0 & l \geq 20 m
\end{array}\right.
$$

\subsection{Discussion on the Stiffness of the Elastic Support}

Factually, the elastic support stiffness changes nonlinearly with the difference between the transverse displacements at each end of suspender and is influenced by many factors such as the main cable stiffness, the tower stiffness and external loads. Therefore, numerical analysis is made on a suspension bridge with MIDAS/CIVIL to explore how $k$ (the elastic support stiffness) changes with different $\Delta$ (transverse displacement difference) and the $k-\Delta$ curve of its suspenders is obtained. As is shown in Figure $4, k$ increases gradually with the increase of $\Delta$ but the increase speed turns to slow down, that is, the $k-\Delta$ curve is a conic curve.

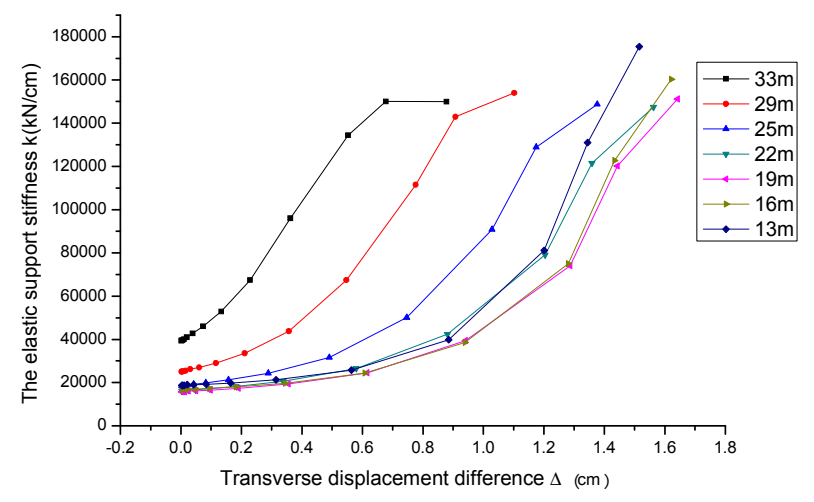

(a)

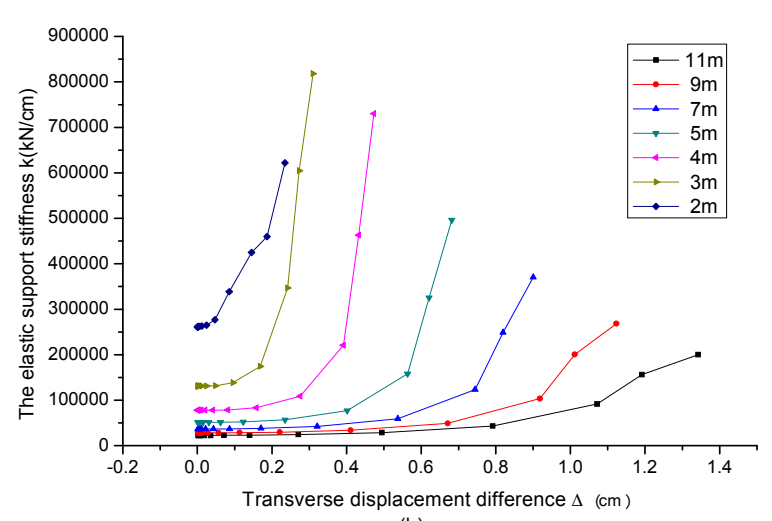

(b)

Figure 4. Variation curve of elastic support stiffness $\mathrm{k}$ with $\Delta$

On the basis of the analysis above, the relationship between $k$ (elastic support stiffness) and $\Delta$ (transverse displacement difference) can be approximately expressed as a conic curve. Obviously, matters will become complex if a conic curve is used to describe the relationship of $k-\Delta$ in engineering. Considering that $k$ locates at the denominator of Equation (1) and the increase of $k$ has tiny impact on $\psi(x)$, the initial tangent stiffness $k_{0}$ can be used to replace the real $k$. In some other words, $k$ can be approximately taken as a constant (Figure 5) that the calculation process can be simplified and meanwhile the calculation accuracy can be guaranteed.

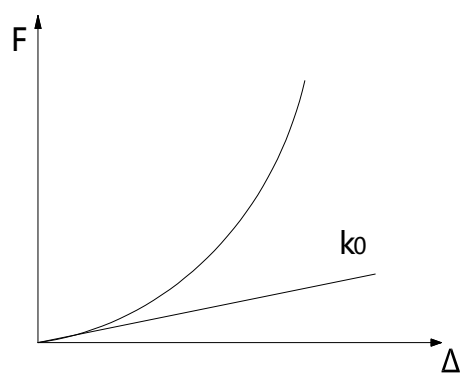

Figure 5. Initial tangent stiffness $k_{0}$

\section{Engineering Example}

Qingcaobei Yangtze river bridge, a suspension bridge with a main span of $245+788+245 \mathrm{~m}$, is a controlling engineering as a part of the expressway from Nanchuan to Fuling and ground anchors are adapted at each bank (Figure 6). It has two main cables which consist of 88 galvanized steel wires and the sag span ratio of the main cable is about $1 / 10$. Orthotropic plate streamlined steel box girder is chose as the stiffening girder which is 30.7 $\mathrm{m}$ in width and $3.5 \mathrm{~m}$ in height. Flexible suspenders are adopted in this bridge, pinned at main cable and stiffening girder. 


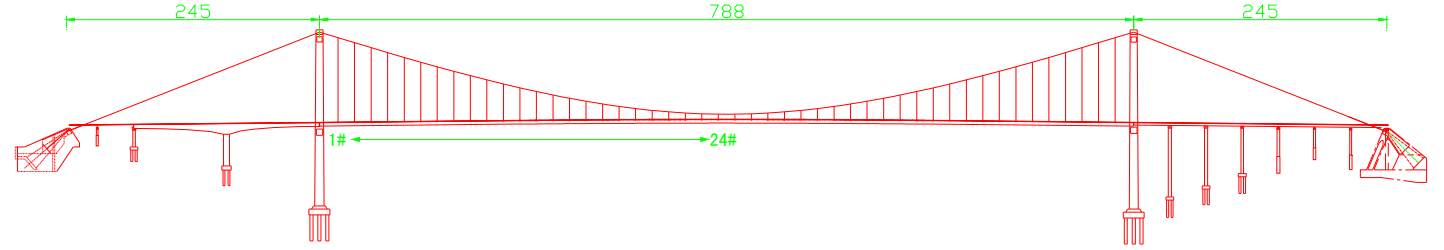

Figure 6. General arrangement diagram of Qingcaobei Yangtze river bridge (Unit: m)

Depending on the elastic support stiffness obtained from the numerical analysis of Qingcaobei Yangtze River Bridge using MIDAS/CIVIL, the suspender forces $\mathrm{T}_{2}$ are calculated by the method proposed in this paper and the traditional calculation method of cable force $\mathrm{T}_{1}$ that can express as the following

$$
T_{1}=4 \pi d^{2} f^{2}-E I \cdot \pi^{2} / l^{2}
$$

Here, the meanings of symbols are the same to the above.

Comparisons between theoretical suspender force and the suspender force calculated by different methods is shown in Table 1 and Figure 7.The suspenders are numbered from 1\# to 24\# as shown in Figure 6.

Table 1. Comparison of theoretical suspender force with the suspender force calculated by different methods

\begin{tabular}{cccccccccc}
\hline $\begin{array}{c}\text { Suspender } \\
\text { number }\end{array}$ & $\begin{array}{c}\text { Theoretical } \\
\text { suspender } \\
\text { force } \\
\text { T0(kN) }\end{array}$ & $\begin{array}{c}\text { Engineering } \\
\text { frequency } \\
(\mathrm{Hz})\end{array}$ & $\begin{array}{c}\text { Initial } \\
\text { tangent } \\
\text { stiffness k0 } \\
(\mathrm{N} / \mathrm{m})\end{array}$ & $\begin{array}{c}\text { Length of } \\
\text { suspender } \\
(\mathrm{m})\end{array}$ & $\begin{array}{c}\text { Mass of } \\
\text { suspender } \\
(\mathrm{kg})\end{array}$ & $\begin{array}{c}\text { Calculating } \\
\text { suspender } \\
\text { force } \\
\mathrm{T} 1(\mathrm{kN})\end{array}$ & $\begin{array}{c}\text { Calculating } \\
\text { (T1-T0)/ }\end{array}$ & $\begin{array}{c}\text { suspender } \\
\text { force } \\
\text { T2(kN) }\end{array}$ & $\begin{array}{c}\text { (T2-T0)/ } \\
\text { T0x100\% }\end{array}$ \\
\hline $1 \#$ & 2553.80 & 0.1802 & 1203048 & 81.1351 & 2925.888 & 2501.27 & $2.1 \%$ & 2542 & $-0.5 \%$ \\
$4 \#$ & 1520.00 & 0.2022 & 543183.1 & 63.5735 & 2292.582 & 1514.52 & $0.4 \%$ & 1556.3 & $2.4 \%$ \\
$7 \#$ & 1541.30 & 0.3001 & 450653.4 & 48.4044 & 1745.551 & 1471.95 & $4.5 \%$ & 1509.3 & $-2.1 \%$ \\
$10 \#$ & 1556.90 & 0.5096 & 527983.1 & 35.6266 & 1284.765 & 1691.41 & $8.6 \%$ & 1546.8 & $-0.6 \%$ \\
$13 \#$ & 1565.00 & 0.8579 & 772200.8 & 25.2517 & 910.6255 & 1704.45 & $8.9 \%$ & 1546.4 & $-1.2 \%$ \\
$16 \#$ & 1562.20 & 1.6717 & 1402525 & 17.2821 & 623.2265 & 2070.08 & $32.5 \%$ & 1556.7 & $-0.4 \%$ \\
$19 \#$ & 1557.00 & 3.2131 & 3484321 & 11.7144 & 422.4439 & 2082.03 & $33.7 \%$ & 1558.5 & $0.1 \%$ \\
$22 \#$ & 1552.90 & 4.9789 & 19955654 & 8.5369 & 307.8571 & 2181.08 & $40.5 \%$ & 1626.7 & $4.8 \%$ \\
$23 \#$ & 1553.20 & 5.2364 & 92783505 & 8.0075 & 288.7653 & 1981.18 & $27.6 \%$ & 1475 & $-5.0 \%$ \\
$24 \#$ & 1551.30 & 5.5643 & 142857100 & 7.7427 & 279.2173 & 2019.99 & $30.2 \%$ & 1503.3 & $-3.1 \%$ \\
\hline
\end{tabular}

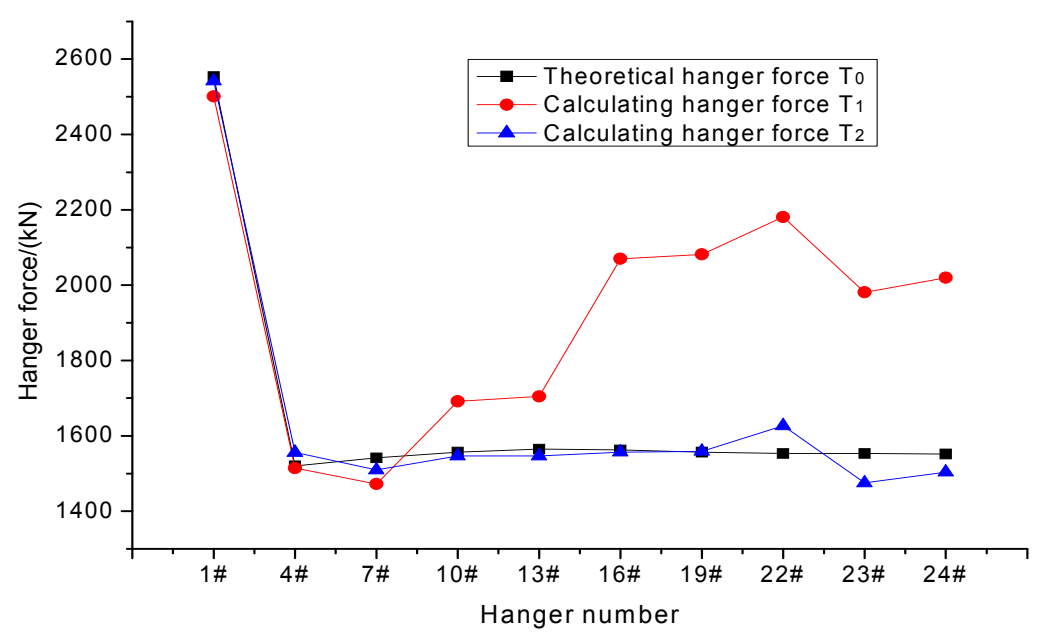

Figure 7. Comparison of theoretical suspender force with the suspender force calculated by different methods

As is shown in Table 1, the calculating suspender force basing on traditional calculation method of cable force has high precision when the suspender is long enough. However, the deviation of suspender force gets greater 
with the decrease of suspender length, which even reached $40.5 \%$ and the results in this case can't be applied in engineering. In this case, traditional calculation method can't be used anymore and the data proves that the method proposed in this paper can meet the precision of suspenders with different lengths and the deviation can be controlled in the engineering allowance.

\section{Conclusions}

On the computation and analysis above, the following conclusion can be drawn.

(1) The model regarding the suspenders as a tensioned beam pinned at one end and elastically supported at the other end fits the real stress states well.

(2) According to the analysis above, it can be obtained that the k- $\Delta$ curve is a conic curve, in which the elastic support stiffness $\mathrm{k}$ increase faster than $\Delta$. The elastic support stiffness $\mathrm{k}$ can be approximately taken as a constant (the initial value of $\mathrm{k}-\Delta$ curve ) to simplify the calculation process and guarantee the computational accuracy.

(3) The method proposed in this paper can meet the precision of suspenders with different lengths, especially to the short suspenders, whose calculation deviation can be controlled in the engineering allowance.

\section{References}

Clough, R. W., \& Penzien, J. (1993). Dynamics of structures (pp. 90-95). New York: McGraw-Hill.

Li, G. H. (1992). Stability and vibration of the bridge structure (pp. 367-396). Beijing: China railway Press.

Li, T. B. (2007). The Research and Practical Application of Frequency Method of Cable Force Measurement (pp. 59-68).

Ren, W., \& Chen, G. (2005). Practical formulas to determine cable tension by using cable fundamental frequency. China Civil Engineering Journal, 38(11), 26-31.

Wang, R. H., Zheng, K. Z., \& Liu, C. H. (2009). Practical Formulas for Estimation of Short Cable Tension by Vibration Method. Science Technology and Engineering, 9(11), 2988-2991.

Wang, X. Q. (2010). Nonlinear and reliability analysis of cable-stayed bridge (pp. 2-32). Beijing: China Communications Press.

\section{Copyrights}

Copyright for this article is retained by the author(s), with first publication rights granted to the journal.

This is an open-access article distributed under the terms and conditions of the Creative Commons Attribution license (http://creativecommons.org/licenses/by/3.0/). 